\title{
The New Global Corporate Culture: A Comparative Survey Of The Corporate Cultures Of Japan And The United States In The $21^{\text {st }}$ Century \\ Michael Wahl, Robert Morris University, USA \\ Nell Tabor Hartley, Robert Morris University, USA
}

\begin{abstract}
Japan 2007, is not the same country it was during the...eighties, when foreigners flocked to Tokyo, armed with copies of books such as How to Succeed in Japan: A Business Etiquette Primer. Globalization, fueled by the Internet and other advances in communications technology, is playing an ever greater role in business operations around the globe. Outside of business, these advances allow people on opposite sides of the globe to interact, and this interaction exposes others to new ideas, views, languages, and cultures. This study evaluates the shifts in the corporate cultures of Japan and the United States, through the framework of Hofstede's value dimensions over the past 25 years, through the use of surveys and interviews in both countries. This rich material is backed by examples of these shifts in both countries; in addition to a brief overview of the communicative differences of Japan and the United States. This study will allow not only business professionals and managers, but also students and teachers, to approach another culture with clear, current insight that gets past stereotypes to help foster success in engaging and working with counterparts in other parts of the world.
\end{abstract}

\section{INTRODUCTION}

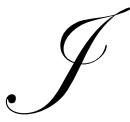
apan 2007, is not the same country it was during the...eighties, when foreigners flocked to Tokyo, armed with copies of books entitled How to Succeed in Japan: A Business Etiquette Primer" (Sanchata, 2007). With the advent of globalization, fueled by the advances in communications technology, the experiences of those foreigners formed the stereotypes of Japan, many of which still survive today. Driven by the economics of employment, and innate curiosity, there is, among students, an increased interest in learning about the values and assumptions of other people. Henry Ford said that, "Coming together is a beginning. Keeping together is progress. Working together is success." While a new generation of managers is seeking the rewards of effective integration of business operations through globalization, students and teachers are engaging in the dynamics of global interaction. It is crucial that we overcome the stereotypes developed and progress, as Ford states, to the point of success that can be achieved by working together.

The primary author of this paper spent a semester studying in Japan and has made a conscientious effort to master the Japanese language. The secondary author serves as a consultant to international businesses and is a professor of organizational behavior. The authors combine their interests to offer a paper that uses Hofstede's work as the frame to compare the possible shifts in the corporate cultures of Japan and the United States over the past 25 years. The research material is rich with information from surveys administered in both countries, and with information gleaned from interviews with several pertinent people. The paper starts with a review of overarching terms involved in the framework of the paper, followed by a brief overview of the communication differences of Japan and the Unites States, a review of the traditional business cultures of both countries in the context of the value dimensions, data collected, and application of the culmination of knowledge. 


\section{DEFINITION OF TERMS}

\section{Hofstede's Value Dimensions}

Geert Hofstede, beginning in the 1960's, conducted research with IBM to survey and analyze information about the cultures from over 70 countries. He identified four main dimensions of a nation's culture. His categorization offers the framework for the paper. The four dimensions framework for the paper are:

Power Distance - A high power distance ranking indicates a society with inequalities of power and wealth, and where significant upward mobility of its citizens is not possible. A low power distance ranking indicates the society promotes equality and opportunity for everyone (ITIM International, 2003).

Individualism versus Collectivism- A high individualism ranking indicates that individuality and individual rights are paramount within the society, encouraging forming a large number of loose relationships. A low individualism ranking typifies societies of a more collectivistic nature, which have close ties between individuals and everyone takes responsibility (ITIM International, 2003).

Uncertainty Avoidance - A high uncertainty avoidance ranking indicates a country has a low tolerance for uncertainty and ambiguity, necessitating a rule-oriented society. A low uncertainty avoidance country is less ruleoriented, more readily accepts change, and takes more and greater risks (ITIM International, 2003).

Masculinity versus Femininity- A high masculinity ranking indicates the country experiences a high degree of gender differentiation; with females being controlled by male domination. A low masculinity ranking indicates the country has a low level of differentiation and discrimination between genders; females and males are treated equally in society (ITIM International, 2003).

\section{VIEWS OF CULTURE}

While Hofstede is not the only expert in the field, his focus on the balance between roles and relationships in culture provides a consistent measurement dichotomy. Table 1 shows the data from Hofstede's original work applying the four core value dimensions to the United States and Japan. The power distance for the United States and Japan are relatively low and similar, as both societies have a large middle class in society. For individualism, the United States scored very high, indicating individualistic tendencies, whereas Japan scored low, indicating that a more group-oriented culture exists. The uncertainty avoidance score for the United States is low, and Japan's is very high. High uncertainty avoidance showcases the tendency to discover all of the details versus trying something on one's instincts. It also shows that the Japanese culture is much less outgoing in general than the United States. Finally, there is the masculinity versus femininity score, showing the United States with a mid-range score and Japan with a very high score'. The high masculinity shows us that Japan has a high focus on achievement, control, and power, as well as indicating that there is a significant schism in the role of the male and female in Japanese society.

Table 1: Value Dimension Scores

\begin{tabular}{ccccc}
\hline Country & Power Distance & Individualism & Uncertainty & Masculinity \\
\hline United States & 40 & 91 & 46 & 62 \\
\hline Japan & 54 & 46 & 92 & 95 \\
\hline
\end{tabular}

(Hofstede, 1980, pp. 26, 53, 84, \& 113)

\footnotetext{
${ }^{1}$ While Japan has a very high masculinity score, as seen in gender roles and the treatment of women, Japanese business culture appears to be highly feminine. This point was discussed and eventually cleared up by Geert Hofstede's son, Gert Jan Hofstede, via e-mail. He explained that while it does appear feminine, this is a result of effects from the other value dimensions (especially collectivism and power distance) and that "the 'good working relationship' does not mean it's cuddly or 'buddy-buddy', as a Westerner might imply" (Gert Hofstede, personal communication February 17, 2006).
} 
What follows is an overview of aspects of traditional business cultures of the United States and Japan and how they coincide with Hofstede's value dimension scores for the country. Understanding the customs of communications provides the most striking comparison.

\section{BUSINESS COMMUNICATION IN THE UNITED STATES}

Business in the United States thrives on the "cold call". From telemarketers to national companies, sales people, administrators, and executives connect with people they have never met before to get information, make proposals, and forge relationships in mere minutes. In many other parts of the world, it would seem ludicrous to call someone without some kind of connection existing in the first place. There are also plenty of opportunities to network through friends and colleagues. It is more "who you know" than "what you know" in business; developing more relationships means power in American business.

A major contrast between Americans and Japanese is that in the United States people are usually blunt, direct, and make their feelings known. This can be further clarified by the following example: a company is losing money and the CEO holds a meeting and states, "No one is buying our widgets! How can we get people to buy them again?" This starts a flurry of suggestions, including making the widgets cheaper from the accounting department to the marketing department wanting them to be more appealing. Finally, the CEO concludes the widgets should be bigger and more appealing (Collins, 1992, p. 79). The previous situation applies to many different aspects of business, such as the want of immediate results. The words chosen determine how others receive, interpret, and respond to a message.

Non-verbal communication tells at least as much as verbal communication through posture, gesture, facial expression, silence, voice quality, interpersonal distance, and dress (Rowland, 1985, p.51). Even when they are lying or remaining silent, Americans often reveal their true feelings non-verbally. In the United States, we are taught to make eye contact. Avoiding eye contact signals a possible lack of sincerity or confidence (Rowland, 1985, p. 53). Finally, the United States views silence as hesitation, and in business it is believed that all silence should be filled regardless of the situation (Rowland, 1985, p.51).

\section{BUSINESS COMMUNICATION IN JAPAN}

Holding a conversation in Japan is complicated by the need to know the other person well enough to show the proper level of respect. The varying levels of politeness used in Japanese business (and in daily life) are briefly explained best by Noriko Kanisawa, a Japanese language instructor:

'To go' in Japanese has three different roots, based on politeness: 1) irassyaimasu (used when the person 'going' is above the speaker in some way), 2) ikimasu (used when the one 'going' is on the same level as the speaker), and 3) mairimasu (usually used when the speaker is the one going). However, it becomes more complicated. There are also informal speech versions of each verb, which are used when speaking to a friend, but the appropriate distance between the speaker and the topic must still be observed. (Noriko Kanisawa, personal communication, June 2004)

In Japan, much more emphasis is put on what is implied than on what is said. This stems from the concept of face, which is the why the Japanese can seem to be indirect, skirting the issue at hand, or even deceptive. Brought up to avoid conflict by all possible means, especially in business, the Japanese are hesitant to directly address problems in presented plans or to refuse an offer, outright. If they are extremely annoyed or frustrated, most Japanese simply smile, because they do not express their true feelings in a public setting (McDaniel \& Quasha, 2000, p. 317). It has been considered inappropriate to use the face as a tool of expression.

Westerners attending a meeting in Japan must be unusually attentive to communication. The Japanese in their initial encounters often bow, ( the degree determined by the seniority) offer a business card. This custom is referred to as meishi. Meishi is not difficult, but performing it correctly is significant nonetheless. When bowing, one offers his or her business card with two hands, face-up. Further, it is imperative that the recipient spends a minute reviewing the card and keeping it intact. Defiling a card in any way is a great disrespect in Japanese culture. 
The other forms of non-verbal communication important in Japanese business are eye contact, sucking in air, and silence. In Japan, looking a boss or teacher directly in the eyes is considered rude; in America someone's not doing this would be construed as being untruthful or lacking confidence. Sucking in air through clenched teeth, which indicates hesitation, especially when used with a drawn out 'so desu ne,' ( a statement marking agreement or acknowledgement with what was said). Silence allows all parties to organize their thoughts and reflect on what has been said. Silence recognizes the importance of face by showing concern or hesitation by sucking in air, which lets the other side bring up an issue, as opposed to pointing it out.

\section{HOFSTEDE'S VALUE DIMENSIONS AND CORPORATE CULTURE}

\section{Power Distance}

In the United States, It is not uncommon for a younger person to be the boss of a senior person. A major determinant of power distance becomes the amount of education that the people have. Japan mainly conforms to an age-based pay and promotion system. The Bank of Japan introduced a merit-based pay system in April of 2005 along with merit-based performance evaluations that are linked to salaries (The Japan Times, June 2004). Yas Ichiura, an export company employee, and Hiroshi Asano, Vice President of DuPont Japan,were interviewed in Japan during December of 2004. Both noted a slow, but apparent, shift to merit-based systems, though many large corporations still adhere to the traditional views. As with all changes, there are unforeseen consequences; with the introduction of merit-based systems and people making mid-life career changes, an interesting issue arises, which is the issue of the mix of age and rank.

In Japan, there is a complicated set of rules for addressing those above and below another in seniority, both in age and rank. There are now situations where a manager is overseeing people who are 15 years his or her senior. How does one react to that and what level of politeness should be used? In response, Ichiura noted, "He would speak to his younger manager as if he is older than him, although it does not feel natural or positive" (2004); however, Asano answered, "Traditionally, a manager would refer to any subordinates by their first name, as do peers, and subordinates would address their manager by his or her family name and -san. Now everyone, aside from close friends, addresses each other by their family names and -san to circumvent the problem caused by having younger managers" (2004).

\section{Individualism Vs Collectivism}

Edward Deming called to the world's attention the difference in the individualisistic tendencies of Americans compared with the more collectivist tendencies of the Japanese. Building on the collectivist mentality, Deming introduced the concept of continuous quality management to Japan and influenced its rise as a manufacturing nation after World War II (Tribus, 1993). He introduced Quality Circles, a team- based approach to quality management.

The collectivistic tendencies of Japanese culture are epitomized in the ideas of in-group \& out-group or uchi \& soto in Japan. This is seen in the workplace and in the various keiretsu (corporate networks) of Japan. Becoming "one of the gang" takes a long time and a great amount of work to develop and sustain. As conformity is the key to success in Japanese society, outsiders are treated with great distrust until they prove themselves trustworthy. The five main types of relationships are: blood relations, demographic relations, colleague relations, teacher-student relations, and classmate relations (Chen and Chung, 2000, p. 304). One must establish a connection through of these categories to do business. "If someone proposes to a company that they can save $\$ 20,000$ a year by using an out-of-group supplier, it is unlikely that the company will buy in. Unlike their counterparts in the United States, the Japanese value as being almost sacred established relationships. (Hiroshi Asano, personal communication, 2004).

In America, lawsuits against companies, groups, and people are commonplace. In Japan, the company head usually steps down if something serious occurs within the company to take responsibility. This serves Japan 
the same way Sarbanes-Oxley Act serves the US; except it originates implicitly from the culture. To illustrate how uncommon lawsuits are in Japan, Robert Collins notes the following true story:

The family left their four-year-old daughter with next-door neighbors. The daughter, playing with the neighbors' children, fell into a stream and drowned. The parents, to everyone's astonishment, sued the neighbors for negligence, and won! The outrage was such that the parents had to give the money back to the neighbors and move out of the community. (Collins, 1992, p. 42)

The Japanese are known for their loyalty to employees and co-workers. Co-workers would rather cover for an underperforming employee than have that person released, thus firings are rare. Despite economic conditions, Japanese companies take losses as a temporary occurrence and releasing a few thousand employees is unfathomable. The ability of companies to deal with losses, even in a long-term economic downturn is mainly through keiretsu, which is described as a "network" approach of the Japanese industry system, characterized by long-term business relationships in which member firms have a high level of coordination in order to manage their non-financial resource flows to create a stable, collective structure of coordinated action centered around a core firm (Hoshino \& Siripaisalpipat, 2004, p. 262)." Keiretsu also exists with major firms that have a network of subsidiaries and suppliers that have forged deep relationships over time, allowing companies to enter into foreign markets and in turn put up the financial and capital assistance to move their entire supply-chain abroad as well (Hoshino \& Siripaisalpipat, 2004, p. 262). When a company can move its supply chain overseas, the uncertainty of creating reliable relationships with domestic suppliers and service providers is taken away, and with the experience and relationship already there, it can start off at a much higher level of efficiency and effectiveness.

\section{Certainty Versus Uncertainty}

Hofstede's dimension of Uncertainty Avoidance is reflected in communication. One of the best examples of the extent to which the Japanese are willing to go to avoid uncertainty is seen in their approaches to decision making. Focusing on the long term and taking an indirect approach are hallmarks of Japanese decision-making. Investments and projects are implemented to produce long-term value for a company; ergo, short-term losses are not seen as a significant problem. When there is a problem, it will be examined in a much slower and drawn out process. Robert Collins gives the following example:

The boss then calls together his key staff... and announces that everyone has stopped buying their widgets. Everyone may agree that to sell more they have to be bigger and prettier. But since that question wasn't even asked... what may happen...is [a consensus is developed] that the widgets are the problem and the company should stop making them. Instead, add a doodad here... and now we are in the...GADGET business! (1992, p. 81)

This shows how the verbiage used can make all the difference. Note that the American CEO in the earlier example asks what needs done to sell more widgets, whereas the Japanese CEO simply states that widgets are not selling. The trade-off on the large amount of time taken in finding and solving problem is that implementation "is merely a matter of pushing a button as implementers are in on the game" (Collins, 1992, p. 81).

It was not until the last quarter of the $20^{\text {th }}$ century that American decision makers began to appreciate the importance of women in adding perspective and enriching corporate strategy. Meachin adds that as of 1998, 84 percent (419) of the Fortune 500 companies had at least one female director. In addition, a 2003 Catalyst report has shown that about 14 percent of all Fortune 500 board seats are filled by women, and the numbers are rising steadily (2005, p.15). Traditionally Japanese women and other minorities have been excluded from the work place.

Successful teams, through diversity, help solve problems that could not be solved by one person alone, "where the tasks being done require multiple skills, judgment and experience" (Saji, 2004, p.40). Historically, the Japanese concept of 'team' excludes the beneficial value of racial and gender diversity. A recent poll indicated more people accept the need for allowing more skilled labor into the country from overseas, though not for the service and unskilled labor markets (The Japan Times, September 2004). 
When asked about lifetime employment, Ichiura replied, "While it is still a popular in the country, and in my company, many younger people are leaving the company for a variety of reasons" (Yas Ichiura, personal communication, December 2004). Asano, the Vice President of DuPont Japan, said that "nowadays employees move between companies and jobs and nothing is made of it. The traditional stigma attached to leaving a company no longer exists" (Hiroshi Asano, personal communication, 2004).

\section{MASCULINITY VS FEMININITY}

Despite numbers indicating that women make up $10.1 \%$ of managers in Japan versus $42 \%$ in the United States (Pacific Bridge, 2007), women are entering the workplace in greater numbers. (Japan is up from $8.9 \%$ in 1995.) In a "Special Report: Japan's Election" in the September 17, 2005 issue of the Economist, it was noted that while women still have fewer opportunities in comparison to the rest of the world, their situation is improving. For example, every week in Japan's biggest business daily, Nihon Keizai Shimbun, has a "working woman" section with career and investment advice (Economist, 2005, p. 24) Japan's view of women's working is changing. A September 2007 survey by The Japan Times indicates that, for the first time, that a majority (52\% overall; $46 \%$ of men \& 57\% of women) oppose women staying home alone. This was compared to a 1979 government survey that produced results indicating a paltry $20 \%$ opposed, with $72 \%$ supporting women staying at home (Kyodo, September 30 , 2007b).

The final issue in masculinity vs. femininity for Japan to be discussed is karoshi, of death by overwork. While it seems unheard of in the United States, it is a significant issue in Japan; officially recognized by the Japanese government in 1987. According to a December 2007 article from the Mainichi News, the spouse of a man thought to have died by karoshi was awarded benefits by the court from the government. The man, who died in 2002 at the age of 30 was working 80 hours of overtime a month in the six months before his death (December 1 , 2007). This provides a stark example of a pitfall of having high masculinity, which correlates into an increased emphasis on achievement, among the other aspects. This issue also has ties to collectivism, in the focus on the group over the individual in Japan, specifically in not letting others down.

All these examples of changes in traditional practices show us that Japan is indeed adaptive. While one will not see an overhaul of the Japanese culture; the economic problems of Japan in the past decade have shown, as Ono \& Spindle's article aptly puts it: Japan's Decline Fuels the Rise of the Individual (2004).

\section{RESEARCH QUESTIONS}

With all this in mind, the following research questions arise:

- $\quad \mathrm{RQ}_{1}$ : What are the values of US and Japanese corporate culture in the $21^{\text {st }}$ century?

- $\quad \mathrm{RQ}_{2}$ : How do these values of US and Japanese corporate culture in the $21^{\text {st }}$ century compare to those values held 25 years ago?

\section{METHODOLOGY}

Based on Hofstede's research there are discernable differences in the corporate culture trends of $21^{\text {st }}$ century United States and $21^{\text {st }}$ century Japan. The design of the survey was developed by the researchers using information gathered through interviews, the review of literature, and the author's experiences studying in Japan.

Due to the scope of this survey, it was necessary to create two surveys, one in English and one in Japanese, with the same content. This was done with the help of Noriko Kanisawa, a professor and student at the University of Pittsburgh, and a number of other contacts. Professional translators reviewed and critiqued the survey. The survey includes rating, on a value scale of one to 10, a brief description of Hofstede's four core value dimensions (power distance, individualism vs. collectivism, uncertainty avoidance, and masculinity vs. femininity) in relation to the participant's culture, as well as rating on a Likert scale, a number of statements concerning corporate culture that 
relate to Hofstede's value dimensions. Finally, there are a few open-ended questions regarding corporate culture in each respective country.

Data were collected using Internet research, well known companies, and networking to find willing participants to respond to the questionnaire via e-mail or post mail, based on the preference of participants. The Japanese open-ended responses were translated into English with the help of a translator. The results of the survey, with a breakdown of the survey sections and appropriate visuals to simplify the data, follow.

\section{RESULTS}

Forty-three responses from the U.S. version and 15 responses from the Japanese survey were usable. Wewill discuss the data obtained from the rating of the dimensions, the Likert scale, and finally some of the most common responses to the open-ended questions.

The first four questions contained descriptions of each of the four value dimensions used in this research and asked respondents to rate them on a scale of one to ten as they felt they applied to American or Japanese business culture (for the U.S. and Japanese surveys respectively). First, it is important to quickly review the results from Hofstede's work. All graphs concerning the value dimensions are scaled with a higher rating corresponding to a high power distance, individualism, high uncertainty avoidance, or masculinity, respectively. The graph below shows the power distance (PD) of both the US and Japan at 40 and 54 respectively, which is relatively low and equal between both. In terms of individualism vs. collectivism (IC) the U.S. is very high at 91 , indicative of a highly individualistic culture. Japan being traditionally collectivistic, is at 46. Next, with uncertainty avoidance (UA), the U.S. is low at 46 and Japan is at 92 , indicating high uncertainty avoidance. Finally, there is masculinity vs. femininity (MF); the U.S. has a moderate rating of 62 and Japan, being highly masculine, has a rating of 95 .

Figure 1: Past Scores for the US \& Japan

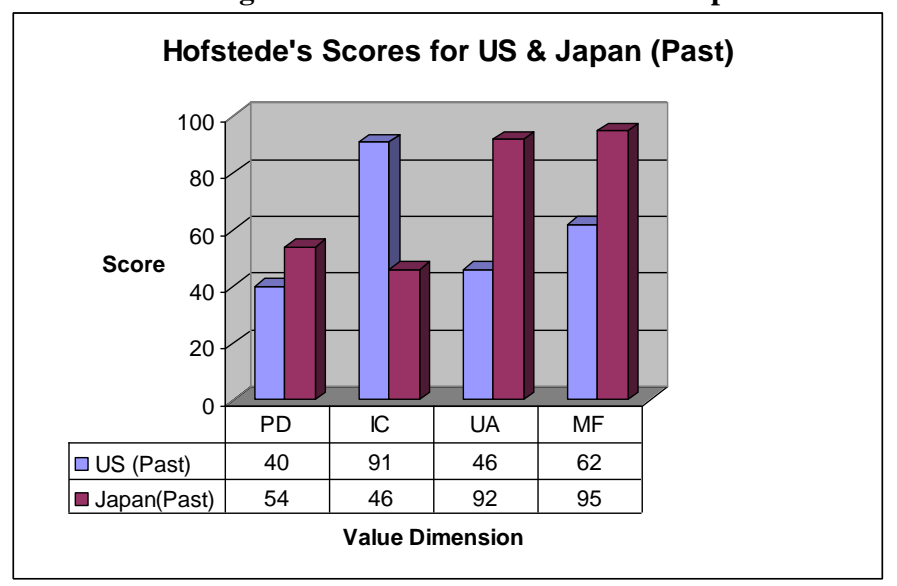

(Hofstede, 1980, pp. 26, 53, 84, \& 113)

A critical point in looking at the data collected for this study versus Hofstede's original work is that the data collected were different in the questions asked and in the scoring (Hofstede's work involves a weighted valuation system). While this makes direct comparison difficult, the data can indicate general relationships between the past and present based on the comparison between the results of the U.S. and Japanese results. This issue will be discussed again in Analysis \& Conclusions. 
Figure 2: Present Ratings for the US \& Japan

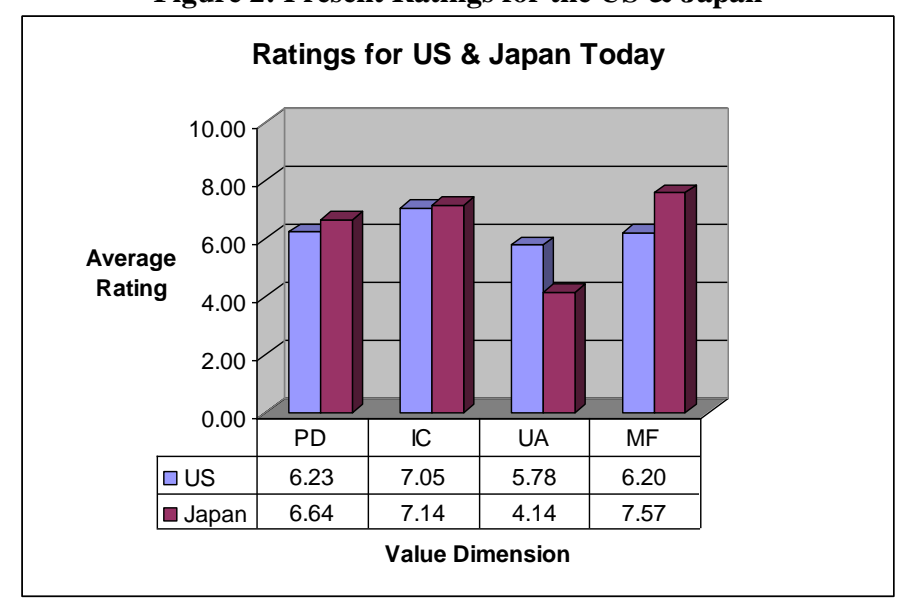

In the current data, power distance in both the U.S. and Japan is about average in rating, with Japan at 6.2 and 6.6, respectively. This appears similar to the past results. This is especially true in Japan where there has traditionally been an extremely large middle class. For individualism vs. collectivism, both had ratings of about 7.1 , which is significant for both countries, with the U.S. seen as a primarily individualistic culture and Japan as a highly collectivistic culture. The U.S. made a small, but significant drop away from individualism, and Japan experienced a large shift away from collectivism to have a slightly higher rating than the U.S. For uncertainty avoidance, the U.S. has a rating of 5.8 and Japan a 4.1. This is interesting, as the rating slightly higher for the U.S. but has had a significant drop for conservative Japan to a rating well below that of the U.S. For masculinity vs. femininity the U.S. and Japan had ratings of 6.2 and 7.6 respectively. The U.S. seems relatively equal and Japan has shifted slightly away from masculinity.

Next, there were 16 statements ranked on a Likert scale which were each related to one the four value dimensions used in this research. The scale ranged from a rating of one for "completely disagree" to four for "agree completely" An average was determined. First there are the results by dimension (Figure 3) and then by statement. For the rankings by dimension, a rating of four indicated high power distance, individualism, high uncertainty avoidance, or masculinity, respectively.

For power distance, the U.S. held an average rating of 2.36 to indicate a moderate power distance with Japan's rating of 2.61, also indicative of a moderate power distance. This is consistent with the moderate ranking for both countries in the past and present. In terms of individualism vs. collectivism, the U.S. had a moderate ranking of 2.23, indicating a slight lean towards collectivism and significantly more collectivistic than Japan, with a rating of 3.08, indicating a disposition towards individualism. This is consistent for Japan, showing a significant shift towards individualism in Figure 2; however, it shows the U.S. as being much more collectivistic then in the past. Uncertainty avoidance in the U.S. had a moderate rating of 2.30 and Japan had a rating of 3.38, indicating high uncertainty avoidance. This shows the U.S. with higher uncertainty avoidance, consistent with Figure 2. Japan has a shift to lower uncertainty avoidance; seen as significantly lower in Figure 2, as compared to the Likert scale where uncertainty avoidance appears to be only slightly lower than past data. Finally, in regards to masculinity vs. femininity, both the U.S. and Japan show a moderate to slight disposition towards masculinity with ratings of 2.74 and 2.93, respectively. This is consistent with previous data, with the U.S. remaining relatively stable and Japan showing noticeable moves away from the high masculinity rating. 
Figure 3: Statement Ratings by Dimension

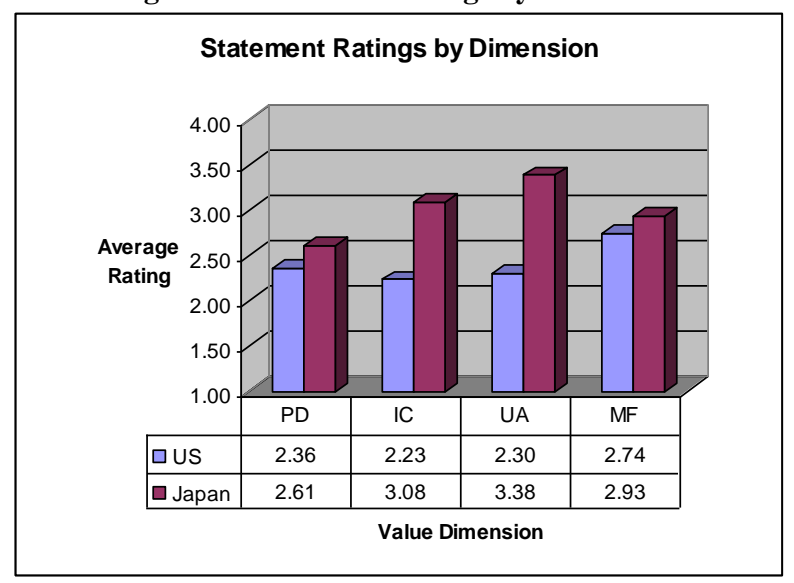

\section{SIGNIFICANT FINDINGS}

The second statement of (People expect more formality in interactions. They like to have structure to things, less chance of the unexpected.") averaged at 3.5 for Japanese respondents and 2.91 for the U.S., reaffirming Japan's high uncertainty avoidance and showing an unusual above-average uncertainty avoidance in the U.S. Statement Seven, (There is a large and growing gap between the rich and the poor.) had an average of 2.64 from Japanese respondents, showing a moderate power distance and agreement with the statement. However, the average from American respondents was 3.4 supporting a significantly high power distance and agreement with the statement. Next, Statement Eight, (Women are treated equally and given the same opportunities for advancement as men in business.) has an average of 2.93 and 2.74 for Japan and the U.S., respectively. This supports insinuations of growing acceptance of women in the workplace in Japan form traditionally very high masculinity ratings. The ranking by U.S. respondents shows no significant change compared to other data. The last three statement relate to collectivism vs. individualism. In Statement 14, (Relationships revolve around being a member of many different groups.) the averages were 2.14 and 1.86 for Japan and the U.S., respectively. Again, in Statement 16, (The company one works for and the people with whom one works act as a second home and family.) Japan had a rating of 3.15 and the U.S., 2.12, backing a significant shift in Japanese business culture towards a more individualistic orientation, especially in relation to the U.S. Finally, Statement 15, (Being accepted into a group as an outsider is very easy.) shows that while certain aspects, in terms of orientation, can change, but that core pieces of the overall societal culture will not. Japanese respondents averaged 1.69 and U.S. respondents averaged 1.88, showing that, while results indicate a more individualistic orientation in Japan, the importance of group membership and relationships between groups still remains important based on the rating of 1.69. This are also seems to be an area of growing importance for U.S. business as well based on the rating of 1.88.

The most common responses to the open-ended questions in the Japanese and U.S. surveys.

The following are the questions asked on both versions of the survey:

1. Do you think that the way U.S. [Japanese] companies operate has changed over the past 10 years? If so, have the changes been significant? Why do you think so?

2. Can you think of any specific business practices which have changed in the U.S. [Japan]? Was this change just by a few groups or was it something that has became the norm in American [Japanese] business?

3. If you had a direct manager or supervisor who was significantly younger than yourself (at least 15 years), do you believe this situation would cause undue tension? And how would you deal or cope with it?

4. Has your company had to change the way it operates in the past 10 years? Why was it felt that things needed to be changed (This refers to major changes in company policy)?

5. Finally, are there and questions or comments? Any additional information you would like to add? 


\section{United States}

In the U.S. version of the survey, question one was answered most frequently with mention of SarbanesOxley, emphasis (both positive and negative) on workforce diversity, and of employers reducing the workforce while using job enlargement to keep the same level of production. In Question Two, again there was reference to Sarbanes-Oxley and internal accountability by the majority of respondents as well as the issue of outsourcing by many companies to stay competitive. In Question Three, respondents were asked about the possibility of tension in reporting to a manager about 15 years their senior. While almost all respondents said it would not be a problem as long as they were experienced or had shown they were capable of performing the job effectively, there were a few that simply stated they would look for another job in that situation. In the fourth question, the majority of responses fell into the categories of an increased focus on ethics and standards inside the company and pressure to operate more effectively and efficiently.

In the final question, asking for any additional information respondents may have had to offer we came across two comments that appeared significant to us. The first statement saying, "Companies are looking for energetic individuals with drive and the will to succeed," indicating that companies are being much more prudent in those they choose, looking for people who are willing to devote themselves to the company and their work and will look to improve themselves and the company as opposed to someone who just wants a paycheck. The second statement was as follows:

Considering the purpose of the questionnaire, I have observed my own responses. In the first area my responses reflect my perception and not necessarily where I think the country is going. In the second set (agree/disagree) my responses are more reflective of my personality style (Meyers Briggs) rather than specifically the society or the business sector. Maybe I am a product of the society.

This is important specifically to the project as a whole because it reinforces the interrelatedness of a society, its people, and the corporate culture. While they may not all be exactly alike, they are each products of the others.

\section{Japan}

In the Japanese version of the survey, responses to the first question mostly involved communications technology, and the movement from a cloistered system of conducting business. They observed greater acceptance of firing unnecessary employees, and shifts from tenure to merit-based systems. One respondent noted in regards to Japan's "closed system" of doing business that "companies realized they could not do it all from a Japanese perspective and started bringing foreigners into companies to help initiate change and move from traditional thinking." In the second question, respondents unanimously indicated that lifelong employment is no longer guaranteed so that workers have less loyalty and are less willing to put in long hours of overtime. In the third question, regarding age in the workplace, the responses indicated that the older, more traditionally thinking generation would respond superficially to a younger boss politely there would still be would discomfort for many because of pride. One respondent noted that change is inevitable. Another respondent brought up an example in Japanese society which shows how the office situation should work. The respondent noted, from personal experience in karate, that someone with higher level skills is spoken to more politely; meanwhile that person would still speak to elders politely. This indicates mutual respect, which backs, Mr. Asano's earlier assertions of all employees speaking politely to each other regardless of position. If they do not respect each other then tension will occur.

Responses to the forth question again focused on the shift from seniority to merit-based systems as well as a greater focus on customers to regain customer trust and loyalty. There was one insightful response to question five, which brought up an interesting point: Japanese companies are trying a combination of practices from other countries and possibly totally new practices.

While the responses to these open-ended questions did not produce the type responses expected, they do offer a significant amount of information on what is important and changing in the corporate cultures of the U.S. and 
Japan. The responses also help reinforce those significant factors in both countries. Next, we will discuss the implications and significance of this research and its results.

\section{RELEVANT EXAMPLES IN THE UNITED STATES}

Recognition of the U.S.'s strengths in diversity and its using it to its full potential affects collectivism positively in terms of creating effective teams in the workplace on all levels, masculinity negatively, in recognizing the importance of women in the workplace, and uncertainty avoidance positively, in helping avoid groupthink and in fostering more prudent decision making by having diverse resources to tap. Fostering the team culture, involving employees, flattening the organizational structure, and the effective use of "just-in-time" have a negative effect on individualism; these four concepts all encourage better communication, and also create constructive conflict by helping divisions and the company as a whole make better decisions. They also help lower the power distance by creating a closer cohesiveness and synergy throughout the company because employees in companies where these environments exist are much more committed to their personal success as well as that of the organization, as seen in the articles in the literature review.

Responses to the open-ended questions show that the power distance is being affected because of the growing distrust of executives and the growing gap between the pay of many executives pay and that of lower-level employees. Finally, in lifelong learning, uncertainty avoidance is affected positively because knowing more about the area in which one works helps one to anticipate problems and be more flexible when issues do arise. Increased knowledge adds to collectivism and lowers power distance.

\section{RELEVANT EXAMPLES IN JAPAN}

Current events that back the significance of the study include the current situations seen in the auto industry; complacent GM and Ford have been consistently losing money and market share to Japanese auto manufacturers Honda, Toyota, and Nissan. The Japanese hold the high ground with their constant innovation and process improvement as Chinese and Indian car manufacturers look to enter the U.S. market.

Women in leadership roles in Japan is in the forefront, because of recent concern that there is not a male heir to the Japanese throne. Two BBC News Online articles present the sides of the issue. A cousin of Emperor Akihito said options such as reintroducing concubines or reintroducing members who left after World War II... should be examined before thinking about allowing a woman to ascend to the throne (BBC News Online, November 3, 2005). Another position is offered in the article from January 20, 2006, in which Prime Minister Junichiro Koizumi pledged to submit a bill to Parliament to allow women to ascend to the throne to ensure the throne can be sustained into the future (BBC News Online, January 20, 2006).

A second case concerning the need to increase the role of women in business (as well as minorities and immigrants) is seen in the population concerns of Japan. According to Kitazume's October 2007 article in The Japan Times, $21 \%$ of the Japanese population is over 65 (over 26 million of the nation's estimated 130 million people). Japan has a fertility rate of 1.26 (October 2, 2007). A couple needs two children to replace themselves in society or a fertility rate of two (2.0). More importantly, according to a 2007 newsletter article by Pacific Bridge, almost $10 \%$ of the Japanese workforce will be retiring in the next five years (October 2, 2007)! The collectivistic culture wishes to remain homogenous by excluding foreigners, despite the need for skilled workers. Is it fear or lack of certainty that drives their determination to prohibit more skilled foreigners into the country especially in critical areas such as medicine. There also may be a fear that allowing foreigners in will cause a shift in the relatively large and complacent middle class that almost all Japanese associate themselves with (through collectivism). Finally, these seem to be a cost associated with the high masculinity of Japan.

The shift by many Japanese companies from lifetime employment has shown that companies are starting to trim staff when necessary. This affects collectivism negatively and increases uncertainty avoidance because the loss of job security. The move to merit-based promotions affects individualism positively and lowers power distance 
since there is a greater focus on individual achievement and with an increased focus on abilities over tenure. As the population declines, more women may be needed in the workforce.

Japan's natural homogeny and its emphasis on not standing out culturally has traditionally equated to a very high collectivism, though with the focus in other areas shifting towards individualism, the homogeny in the workplace is changing. This leads to a more individualistic workplace. Companies who moved to a faster decision making model were able to adapt more quickly and become more flexible, which again adds to individuality. Finally there is the lack of specialization, seen through the widespread use of work teams where all members have similar, vague job descriptions and where the overall culture is seen as highly collectivistic. The shift to a more specialized work environment has been seen through a growing focus on individual achievement and in the cell manufacturing methods used by Cannon (Asano, personal communication) and by some television manufacturers (Kenney, 2004, p. 272).

\section{CONCLUSION}

Summarizing the results of the survey, the U.S. saw a small increase in power distance and uncertainty avoidance, a moderate drop from high collectivism, and a relatively steady level of masculinity vs. femininity. Compared to past data, Japan appeared stable in power distance, with a significant increase in uncertainty avoidance, a moderate shift away from collectivism, and a moderate shift away from masculinity. Compared to the Likert results, there was negligible difference in terms of power distance, individualism vs. collectivism, and masculinity vs. femininity. However there was a difference in terms of uncertainty avoidance with results indicating moderately higher uncertainty avoidance.

Japan is still the second largest economy in the world and will not completely shed its traditional culture. Some of these changes specifically, a greater focus on individual rights and a higher propensity for employees to speak their minds, (a definite departure from the traditional collectivistic notion to avoid starting conflict or causing someone else to lose face) will cause restlessness and problems for some.

There are definite signs supporting changes in the corporate cultures of the U.S. and Japan moving into the $21^{\text {st }}$ century. The implications of this study, from a management standpoint, are seen in current events and in the fact that managers, particularly in international companies, need to know what their workers expect from a workplace environment to minimize alienation of employees and other impairments to productivity. Clearly personalities of different cultures is crucial for managers in effectively working with others. The results of this study provide insights for improvements to be made to better the workplace and company.

For those conducting business, studying, or teaching abroad, the results indicate that Japan's and the United States' corporate cultures appear to have seen some changes over the past quarter century. More specifically, the stereotypes of the past do not apply today. Globalization and Japan's economic growth were the catalyst for coming together. The results of this study offer a guide to help people from across the world "keep together and progress". Combined, closer collaboration is fostered, not just in business, but also across disciplines. Collaboration will increase the likelihood of success; just as Henry Ford stated: "Coming together is a beginning. Keeping together is progress. Working together is success."

\section{REFERENCES}

1. Asian HR eNewsletter. (2007, October 2). Woman look to play a bigger role in Japan's talent pool. [Posted on Web site Pacific Bridge]. Retrieved October 8, 2007, from http://www.pacificbridge.com/ newslettervol.asp? vol $=7 \&$ no $=10$

2. Associated Press. (2007 December, 1). Japanese court orders government to pay compensation for Toyota worker's death from overwork. Mainichi Online. Retrieved December 1, 2007 from http://mdn.mainichi.jp/ national/news/20071201p2a00m0na023000c.html

3. BOJ plans merit-based pay system. (2004, 19 June). The Japan Times Online. Retrieved June 21, 2004, from http://www.japantimes.co.jp/cgi-bin/getarticle.pl5?nb20040619a3.htm 
4. Chen, G. \& Chung, J. (2000). The 'Five Asian Dragons': Management Behaviors and Organizational Communication. In Porter, R.E., \& Samovar, L.A. (Eds.). Intercultural Communication: A Reader (pp. 301-312). Belmont, CA: Wadsworth Publishing Company.

5. Collins, R. (1992). Japan-think Ameri-think: An irreverent guide to understanding the cultural differences between us. New York: Penguin Books.

6. .Ethridge, M. (2005, April 3). Managers create new cultures at work. Akron Beacon Journal, p. I8, April 3, 2005. Retrieved October 3, 2005, from Business NewsBank database.

7. Grobman, M. (2005, February 1). Diverse groups creating business diversity. Mercer Business, 81(2), 6. Retrieved October 3, 2005, from Business NewsBank database.

8. Gross, A. (2007, August). Asian Cultural Diversity in Human Resource Management. [Posted on Web site Pacific Bridge]. Retrieved October 30, 2005, from http://www.pacificbridge.com/publication.asp?id=91

9. Hofstede, G. (2001). Culture's consequences: Comparing values, behaviors, institutions, and organizations across nations. Thousand Oaks, CA: Sage Publications.

10. Hofstede, G. (2003). Cultural dimensions. [Posted on Web site of ITIM International]. Retrieved Oct 23, 2004, from http://www.geert-hofstede.com/hofstede dimensions.php

11. Hoshino, Y. \& Siripaisalpipat, P. (2000, 9-10 June). Entry strategy in the view of networking relationship and stability of Japanese manufacturing affiliates in four ASEAN countries (pp. 261-275). Paper presented at the 2000 AJBS Conference Best Papers Proceedings, Oiso, Kanagawa, Japan.

12. Japan bill to let women on throne. (2006, January 20). BBC News Online. Retrieved January 20, 2006, form http://news.bbc.co.uk/1/hi/world/asia-pacific/4630464.stm

13. Japan female succession queried. (2005, November 3). BBC News Online. Retrieved November 3, 2005, from http://news.bbc.co.uk/1/hi/world/asia-pacific/4403366.stm

14. Kenney, M. (1999, June). Transplantation: A comparison of Japanese television assembly plants in Japan and the United States. In Adler, P., Fruin, W.M., \& Liker, J, (Eds.). Remade in America (pp. 257-293). New York: Oxford University Press.

15. Kitazume, T. (2007, October 2). Population woes said best served by aiding women. The Japan Times Online. Retrieved October 2, 2007, from http://www.japantimes.co.jp

16. Kyodo. (2007, September 30b). Survey shows 52\% oppose wives staying home alone. The Japan Times Online. Retrieved September 30, 2007, from http://www.japantimes.co.jp

17. Lewis, L. (2005, December 27). Japan backs gender equality plan. BBC News Online. Retrieved December 28, 2005, from http://news.bbc.co.uk/ 2/hi/asia-pacific/4561726.stm

18. McDaniel, E.R., \& Quasha, S. (2000). The communicative aspects of doing business in Japan. In Porter, R.E., \& Samovar, L.A. (Eds.). Intercultural Communication: A Reader (pp. 312-324). Belmont, CA:

Wadsworth Publishing Company.

19. Meachin, D. (2005, September). Globalizing the Boardroom: The Case for a New Kind of Diversity. Directorship, 31(8), p. 14-15.

20. Ono, Y. \& Spindle, B. (2001, 1 March). Japan's decline fuels the rise of the individual. Career Journal Asia. Retrieved April 6, 2004, from http:// www.careerjournaleurope.com/myc/workabroad/20010301ono.html

21. Pollees warm to foreign labor influx and tighter controls. (2004, September 14). The Japan Times.

22. Rowland, D. (1985). Japanese Business Etiquette. New York: Warner Books.

23. Saji, B. (2004), Workforce diversity, temporal dimensions and team performance. Cross Cultural Management, 11(4), 40-59.

24. Sanchanta, M. (2007, April). Japanese value relationships and quality time. Financial Times. Retrieved October 8, 2007, from ProQuest Direct Database.

25. Special Report: Japan's Election. (2005, September 17). Economist, September 17, 2005, pp. 6, $23-24$.

26. Tribus, M. (1993). W. Edwards Demming. [Article posted on Web site Clemson Continuous Quality Improvement Server]. Retrieved October 30, 2005, from http://deming.ces.clemson.edu/pub/den/nae_memorial.pdf 


\section{NOTES}

